\title{
The Effects of Chess Instruction on Pupils' Cognitive and Academic Skills: State of the Art and Theoretical Challenges
}

\author{
Giovanni Sala ${ }^{1 *}$, John P. Foley ${ }^{2}$ and Fernand Gobet ${ }^{1}$ \\ ${ }^{1}$ Department of Psychological Sciences, University of Liverpool, Liverpool, UK, ${ }^{2}$ Chess in School \& Communities, \\ London, UK
}

Keywords: chess, cognition, academic achievement, meta-analysis, placebo effect

\section{INTRODUCTION}

Chess instruction has been claimed to enhance primary and middle school students' mathematical abilities. The "Chess Effect" hypothesis has received some scientific support but it is yet to be convincingly demonstrated. This note briefly reviews the prevailing research, identifies some common pitfalls, and recommends directions for future research.

Mathematics proficiency is seen as a necessary prerequisite for gaining jobs in the Science, Technology, Engineering and Mathematics (STEM) disciplines, which underpin our technological future. While the level of the required mathematical skills is increasing, the global educational surveys PISA and TIMSS have documented striking differences in proficiency levels between countries, which have created concern in several countries on their relative performance in mathematics. For example, from the USA perspective, researchers have conducted comparative analyses of performance trends (Hanushek et al., 2012) and also of mathematics pedagogy (Richland et al., 2012). There is a general feeling that novel methods of teaching have to be developed to make mathematics instruction more effective.

Edited by:

Petko Kusev

Kingston University, UK

Chess instruction in school has been proposed as an intervention to address this objective.

Reviewed by:

Alexey Root,

University of Texas at Dallas, USA The conventional wisdom that chess instruction may enhance pupils' academic performance has stimulated numerous research projects worldwide over the last two decades. Most of the studies have focused on the putative benefits of chess instruction on achievement in mathematics.

\section{*Correspondence:}

Giovanni Sala

giovanni.sala@liv.ac.uk

Specialty section:

This article was submitted to

Cognition,

a section of the journal

Frontiers in Psychology

Received: 22 January 2017 Accepted: 07 February 2017 Published: 23 February 2017

Citation:

Sala G, Foley JP and Gobet F (2017)

The Effects of Chess Instruction on

Pupils' Cognitive and Academic Skills:

State of the Art and Theoretical

Challenges. Front. Psychol. 8:238.

doi: 10.3389/fpsyg.2017.00238

\section{A META-ANALYSIS OF THE AVAILABLE EVIDENCE}

A recent meta-analysis has evaluated the effectiveness of chess instruction (Sala and Gobet, 2016). The meta-analysis, including 24 studies and 40 effect sizes, shows that chess does seem to enhance primary and middle school students' achievement in mathematics $(\bar{d}=0.38)$ and overall cognitive ability $(\bar{d}=0.34)$. The effects on achievement in literacy appear to be modest $(\bar{d}=0.25)$. Moreover, the size of the effects is positively related to the amount of training, suggesting that $25-30 \mathrm{~h}$, equivalent to a lesson per week during the school year, is probably the minimum threshold to obtain meaningful benefits. However, in spite of the promising results, this meta-analysis also points out that almost none of the reviewed studies compared chess-treated groups with active control groups to rule out possible placebo effects. At present, this is the most serious methodological issue in the field.

\section{THE IOE STUDY}

A new study by the Institute of Education, London (the "IoE study") has challenged the Chess Effect hypothesis (Jerrim et al., 2016). The study compared a large group of Year 5 pupils (age 9/10) 
( $N=1,965)$ engaging in 1 year of chess instruction $(25-30 \mathrm{~h})$ with a passive control group of peers $(N=1,900)$. The school classes were randomly assigned to the two groups and pretested via Key Stage 1 public examinations for literacy, science, and mathematics. One year after the end of the treatment, the participants were post-tested via Key Stage 2 public examinations in the same disciplines. The two groups did not differ in any of the outcome measures. This result attracted some attention from the UK press (e.g., Pells, 2016) because it contradicts not only the previous research, but also the common view of many head teachers and educationists about the presumed benefits of chess. For these reasons, this study is worth some further discussion.

The IoE study possesses some strengths: a large sample, administrative data for both the pre-test and the post-test, and group allocation by randomization. However, there are two major weaknesses in the experimental design that lead us to doubt the reliability of the null results, especially in relation to mathematics. First, as previously mentioned, the post-test was administered 1 year after the end of the instruction. Thus, the IoE study sought to derive the "long-term" impact of chess instruction. However, the lack of an immediate post-intervention measure allows no direct comparison with previous studies, as the literature has focused on the short-term impact. Previous research indicates that $25-30 \mathrm{~h}$ of instruction and play is the minimum required to gain a significant short-term impact (Sala and Gobet, 2016). Hence, it is improbable that the same amount can induce a long-term impact. Second, the results may be vitiated by a ceiling effect. The IoE study reported an overall mean of $70 \%$ and a standard deviation $20 \%$ in Key Stage 2 mathematics. Moreover, the distribution was highly negatively skewed (Jerrim et al., 2016, Figure 2, p. 27), with approximately half of the sample performing above $75 \%$. These sample scores are consistent with those at the national level published by the Department for Education (for details, see Statistics: key stage $2,2017^{1}$. Given that the exam system generates an artificially constrained distribution of test results, measuring the effect of any intervention is problematic.

\section{UNRESOLVED ISSUES OF THE RESEARCH ON THE BENEFITS OF CHESS INSTRUCTION}

Even if the IoE study does not provide any clear evidence against the alleged benefits of chess instruction, the evidence produced so far is insufficient to establish those benefits either. Some essential design-related and theoretical questions are yet to be resolved.

\section{The Problem of Placebo Effects}

Apart from this single IoE study, previous research on the effects of chess instruction plausibly indicates a positive impact on mathematics performance. However, we cannot rule out placebo effects because almost none of the experiments in the field of chess and education were designed with active control groups. (The exception is Sala et al., 2016, where the chess group was

${ }^{1}$ https://www.gov.uk/government/collections/statistics-key-stage-2) compared to both a passive control group and a group playing go.) All the qualitative analyses, including the IoE Study, show that most pupils are enthusiastic about chess. This enthusiasm may make the pupils more motivated about school-which in turn boosts academic performance. Many other activities may be as motivating as chess and, hence, obtain the same positive results.

The necessity of active control groups to control for placebo effects goes beyond the particular case of chess and encompasses training interventions in general (Moreau et al., 2016). Crucially, it has been recently observed that the type of control group (active or passive) is often a significant moderator in metaanalytical models. For example, comparisons between treatment and active control groups systematically provide smaller effect sizes than comparisons between treatment and passive control groups in domains such as working memory training and music instruction (Melby-Lervåg et al., 2016; Sala and Gobet, 2017a).

\section{The Lack of a Cognitive Link}

The generalization of chess skill to the domain of mathematics would be an example of far transfer. Far transfer occurs when a set of skills generalizes across domains only loosely related to each other (Thorndike and Woodworth, 1901; Anderson, 1990; Barnett and Ceci, 2002). Substantial research on transfer has strongly suggested that far transfer occurs, but rarely and with minimal effects (Donovan et al., 1999; Gobet, 2016). Examples of failed far transfer include music instruction to improve children's (aged 3-14) cognitive ability or academic achievement (Sala and Gobet, 2017a) and working memory training to enhance overall cognitive ability (Melby-Lervåg et al., 2016; Sala and Gobet, 2017b).

So, why should chess instruction improve academic performance? The proposed explanations refer to the fact that chess is a cognitively demanding activity. Chess requires domain-general cognitive abilities that may be trained by the practice of the game. Then, those cognitive abilities may transfer to other domains. For example, Bart (2014) suggests that chess involves, and possibly boosts, cognitive abilities such as working memory, fluid intelligence, and concentration capacity (see also Burgoyne et al., 2016; Sala et al., in press). These abilities are predictors of achievement in mathematics (e.g., Deary et al., 2007; Peng et al., 2016), which would explain why chess increases pupils' mathematical ability. A similar argument is deployed in the IoE Study (Jerrim et al., 2016; p. 6 et seq.). Chess may be beneficial for mathematical ability and, more widely, academic achievement by enhancing concentration and problem-solving skills.

These explanations, albeit lacking detail, are plausible and provide the basis for the hypothesis that chess instruction strengthens cognitive abilities that are positively correlated to achievements in mathematics. Unfortunately, only a few studies have investigated the effects of chess on both cognitive abilities and academic outcomes. The results so far have been mixed (Scholz et al., 2008; Sala et al., 2016). In brief, the causal mechanisms remain substantially untested. 


\section{RECOMMENDATIONS FOR FUTURE RESEARCH}

Combining the research results so far, we may conclude that exposure to chess instruction is associated with positive results in mathematics performance in the general population of primary and middle school students in the short term but not in the long term. Consequently, the validation of chess as an educational tool must undergo further research. A rigorous experimental design is needed to shed some light on (a) the potential placebo effects of chess instruction, (b) the cognitive mechanisms underlying the transfer from chess to mathematics skills, and (c) the appropriate type and duration of the teaching for this transfer to occur.

An active control group is necessary to understand whether the observed impact on pupils' achievement in mathematics is chess-specific or due to placebo effects (Gobet and Campitelli, 2006). Chess could be matched against another enrichment activity such as music or drama lessons. However, such a design would not rule out the possibility that both the treatments are equally effective for treatment-specific reasons and not just for placebo effects (e.g., because chess instruction enhances fluid intelligence and music training enhances spatial skills).

Another option is to compare the effects of chess with and without instruction. While exposure to unstructured chess activities (e.g., free play with peers) is not supposed to provide any particular benefit apart from placebo effects, a set of chess activities specifically designed to train cognitive/academic skills may be more effective. This design is the equivalent of the one often used in the field of working memory training (e.g., Jaeggi et al., 2011), where the effects of treatment are compared to the ones exerted by a non-adaptive version of the training program. The exposure of both the groups to the same stimuli (e.g., chess boards, pieces, playing games) guarantees the isolation of the placebo effects. Moreover, using two different versions of the

\section{REFERENCES}

Anderson, J. R. (1990). Cognitive Psychology and its Implication (3rd Edn). New York: Freeman.

Barnett, S. M., and Ceci, S. J. (2002). When and where do we apply what we learn? A taxonomy for far transfer. Psychol. Bull. 128, 612-637. doi: 10.1037/0033-2909.128.4.612

Bart, W. M. (2014). On the effect of chess training on scholastic achievement. Front. Psychol. 5:762. doi: 10.3389/fpsyg.2014.00762

Burgoyne, A. P., Sala, G., Gobet, F., Macnamara, B. N., Campitelli, G., and Hambrick, D. Z. (2016). The relationship between cognitive ability and chess skill: a comprehensive meta-analysis. Intelligence 59, 72-83. doi: 10.1016/j.intell.2016.08.002

Deary, I. J., Strand, S., Smith, P., and Fernandes, C. (2007). Intelligence and educational achievement. Intelligence 35, 13-21. doi: 10.1016/j.intell.2006.02.001

Donovan, M. S., Bransford, J. D., and Pellegrino, J. W. (1999). How People Learn: Bridging Research and Practice. Washington, DC: National Academies Press.

Gobet, F. (2016). Understanding Expertise: A Multi-Disciplinary Approach. London: Palgrave/Macmillan.

Gobet, F., and Campitelli, G. (2006). "Educational benefits of chess instruction. A critical review," in Chess and Education. Selected Essays from the Koltanowski Conference ed T. Redman (Dallas, TX: University of Texas at Dallas), 124-143. same activity allows the same person(s) to deliver the treatment to both the groups, instead of a chess instructor for the chess group and another expert for the active control group. The advantage of this approach is that it allows us to control for possible Pygmalion effects.

With regard to the cognitive benefits of chess instruction, the empirical evidence is quite sparse. Future studies should investigate the effects of chess instruction on a wide set of cognitive skills related to mathematics, such as fluid intelligence, planning, working memory, and spatial ability. Multivariate measures of mathematical ability would help to understand the particular mathematical skills enhanced by chess instruction (e.g., logical analysis, problem-solving, arithmetic, geometry). A welldefined and testable causal model linking chess, cognitive and academic skills is needed. Such a model is essential to tailor effective methods for chess instruction.

The didactic methods in the teaching experiment should fulfill the requirements of common elements across domains for transfer to occur. Hence, they should incorporate those features that chess shares with mathematics such as the geometry of tactical patterns, the exchange value of pieces and problemsolving situations (Root, 2008; Sala et al., 2015; Trinchero and Sala, 2016). Examining various measures of chess skills (e.g., piece positioning, tactics, strategy) is required to link specific chess activities to the particular cognitive/academic skills. A systematic measuring scheme is required relating the quantum of chess instruction (e.g. 15, 30, $45 \mathrm{~h}$, etc.) and the duration of the effect $(0,6,12$ months, etc.). Such a design would make a major contribution to our comprehension of the Chess Effect (if any).

\section{AUTHOR CONTRIBUTIONS}

GS wrote the first draft of the paper. All authors listed have made substantial, direct and intellectual contribution to the work, and approved it for publication.

Hanushek, E. A., Peterson, P. E., and Woessmann, L. (2012). Achievement Growth: International and US State Trends in Student Performance. Harvard's Program on Education Policy and Governance.

Jaeggi, S. M., Buschkuehl, M., Jonides, J., and Shah, P. (2011). Short- and long-term benefits of cognitive training. Proc. Natl. Acad. Sci. U.S.A. 108, 10081-10086. doi: $10.1073 /$ pnas. 1103228108

Jerrim, J., Macmillan, L., Micklewright, J., Sawtell, M., and Wiggins, M. (2016). Chess in Schools. Evaluation Report and Executive Summary. Education Endownment Foundation. Available online at: https:// educationendowmentfoundation.org.uk/public/files/Projects/Evaluation_ Reports/EEF_Project_Report_Chess_in_Schools.pdf

Melby-Lervåg, M., Redick, T. S., and Hulme, C. (2016). Working memory training does not improve performance on measures of intelligence or other measures of far-transfer: evidence from a meta-analytic review. Perspect. Psychol. Sci. 11, 512-534. doi: 10.1177/1745691616635612

Moreau, D., Kirk, I. J., and Waldie, K. E. (2016). Seven pervasive statistical flaws in cognitive training interventions. Front. Hum. Neurosci. 10:153. doi: 10.3389/fnhum.2016.00153

Pells, R. (2016). Playing Chess does not Make Children Clever, Study Finds. Available online at: http://www.independent.co.uk/news/education/education-news/ playing-chess-does-not-make-children-cleverer-study-finds-a7134176.html

Peng, P., Namkung, J., Barnes, M., and Sun, C. Y. (2016). A meta-analysis of mathematics and working memory: moderating effects of working memory 
domain, type of mathematics skill, and sample characteristics. J. Educ. Psychol. 108, 455-473. doi: 10.1037/edu0000079

Richland, L. E., Stigler, J. W., and Holyoak, K. J. (2012). Teaching the conceptual structure of mathematics. Educ. Psychol. 47, 189-203. doi: 10.1080/00461520.2012.667065

Root, A. W. (2008). Science, Math, Checkmate. 32 Chess Activities for Inquiry and Problem Solving. Westport, CT: Teacher Ideas Press.

Sala, G., Burgoyne, A. P., Macnamara, B. N., Hambrick, D. Z, Campitelli, G., and Gobet, F. (in press). Checking the "Academic Selection" argument. Chess players outperform non-chess players in cognitive skills related to intelligence: a meta-analysis. Intelligence. doi: 10.1016/j.intell.2017.01.013

Sala, G., and Gobet, F. (2016). Do the benefits of chess instruction transfer to academic and cognitive skills? A meta-analysis. Educ. Res. Rev. 18, 46-57. doi: 10.1016/j.edurev.2016.02.002

Sala, G., and Gobet, F. (2017a). When the music's over. Does music skill transfer to children's and young adolescents' cognitive and academic skills? A metaanalysis. Educ. Res. Rev. 20, 55-67. doi: 10.1016/j.edurev.2016.11.005

Sala, G., and Gobet, F. (2017b). Working memory training in typically developing children: a meta-analysis of the available evidence. Dev. Psychol. doi: 10.1037/ dev0000265. [Epub ahead of print].

Sala, G., Gobet, F., Trinchero, R., and Ventura, S. (2016). "Does chess instruction enhance mathematical ability in children? A three group design to control for placebo effects," in Proceedings of the $38^{\text {th }}$ Annual Meeting of the Cognitive Science Society. (Philadelphia, PA).
Sala, G., Gorini, A., and Pravettoni, G. (2015). Mathematical problemsolving abilities and chess. SAGE Open 5, 1-9. doi: 10.1177/21582440155 96050

Scholz, M., Niesch, H., Steffen, O., Ernst, B., Loeffler, M., Witruk, E., et al. (2008). Impact of chess training on mathematics performance and concentration ability of children with learning disabilities. Int. J. Spec. Educ. 23, $138-148$.

Thorndike, E. L., and Woodworth, R. S. (1901). The influence of improvement in one mental function upon the efficiency of other functions. (I). Psychol. Rev. 8, 247-261. doi: 10.1037/h0074898

Trinchero, R., and Sala, G. (2016). Chess training and mathematical problemsolving: the role of teaching heuristics in transfer of learning. Eur. J. Math. Sci. Technol. Educ. 12, 655-668. doi: 10.12973/Eurasia.2016.1255a

Conflict of Interest Statement: The authors declare that the research was conducted in the absence of any commercial or financial relationships that could be construed as a potential conflict of interest.

Copyright (c) 2017 Sala, Foley and Gobet. This is an open-access article distributed under the terms of the Creative Commons Attribution License (CC BY). The use, distribution or reproduction in other forums is permitted, provided the original author(s) or licensor are credited and that the original publication in this journal is cited, in accordance with accepted academic practice. No use, distribution or reproduction is permitted which does not comply with these terms. 